\title{
A Framework for Healthcare Supply Chain Improvement in Thailand
}

\author{
Duangpun Kritchanchai \\ Department of Industrial Engineering, Mahidol University \\ 25/25 Phutthamonthon 4 Rd. Phutthamonthon Salaya Nakhonpathom 73170, Thailand \\ Fax. +662-889-2138 ext 6709, Tel. +662-889-2138 ext 6246 \\ duangpun.skr@mahidol.ac.th
}

\begin{abstract}
Logistics and supply chain management has become a competitive tool in many industries in Thailand. Supply chain perspective has led the industry to see through the process integration from upstream to downstream. In Thailand, healthcare supply chain has only been introduced to hospitals. Operations and co-ordinations across players have still been neglected. The supply chain concept for this industry is in a very early stage. It is evidenced that healthcare industry in Thailand still suffers from inefficient process, inconsistent and inaccurate data information. Lacking of transparency throughout the chain makes it difficult to track and trace patient data and product data. Furthermore, each player in healthcare supply chain, manufacturers, wholesalers, distributors, healthcare providers, tends to develop its own data communicating language. Therefore it discourages the player to communicate and share information with its partner. The lack of integrity in supply chain has become a facilitating factor for the growing problem of counterfeiting. It is undeniable that an influx of counterfeit drug affects both public and private sectors negatively. This problem not only leads to economic loss but also has a negative impact on patient safety in Thailand. The purpose of this paper is to review problems that occurred in healthcare area regarding to supply chain management and identify challenges. It is found that standardised drug coding, operational re-engineering and implementing information technology are promising performance improvement in healthcare supply chain. The paper develops a framework for healthcare supply chain improvement in Thailand. It urges both policy makers and implementers to realize national health problems as well as identify rooms for further research and improvement.
\end{abstract}

Keywords: supply chain management, healthcare supply chain, standard drug code

\section{INTRODUCTION}

Logistics and supply chain management has become increasingly important in recent years as supply chain perspective has led the industry to see through the process integration from upstream to downstream. Due to this strategy, it enhances trading partners to share their information and cooperate to improve efficiency of the supply chain. Effective co-ordination along the chain has played an important role in focusing on the innovation, flexibility and speed that bring about the competitive advantage necessary for survival in a competitive business world (Turhan and Vayvay, 2009).
Supply chain management is more complex in healthcare industry. In this area, companies and hospitals have to do highly accurate job as cost of error might be someone's life (Mustaffa and Potter, 2009; Turhan and Vayvay, 2009). In Thailand, healthcare industry has been regarded partially in hospital. Operations and co-ordinations across players have been neglected. The supply chain concept has just been introduced to this industry at an early stage. It is evidenced that healthcare industry in Thailand still suffers from inefficient process, inconsistent and inaccurate data information. This idea is supported by one of the biggest state-owned hospital's case study in Thailand. The case study shows that there is lack of proper inventory management and an inefficient internal supply chain (Kritchanchai and Suwandechochai, 2010).

Gattorna (1998) describes a healthcare business as it is provided by a variety of product and service enterprises including medical consumables, pharmaceuticals, catering, laundry cleaning, waste management, home-care products, information technology, vehicle fleet management and general supply. A typical supply chain is a complex network consisting of many different parties at various stage of the value chain (Kritchanchai and Suwandechochai, 2010; Rossetti, 2008; Mustaffa and Potter, 2009; Turhan and Vayvay, 2009; Burns et al., 2002). Generally, healthcare supply chain has similar core structure likewise other industries' supply chain as it composed of input, process and output. There are material flow and information flow along the chain (Kritchanchai and Suwandechochai, 2010). Under the concept of supply chain management, the merchandise is produced and delivered in the right quantities, to the right location and at the right time (Rossetti, 2008). However, Turhan and Vayvay (2009) state that it is a must in healthcare industry as a cost of error might be someone's life. They also mention that healthcare supply chain management differs from other application in term of key elements as it tends to be misalignment, high costs for healthcare providers and heavy dependence on third party.

According to Mustaffa and Potter (2009) and Burns et al. (2002), the four major types of players are manufacturers, distributors, healthcare providers and payers. The typical supply chain is illustrated in Figure 1. Manufacturers include primary and secondary manufacturers. Primary manufacturer refers to any manufactures that involves the creation of active ingredient contained within the medications. The primary manufacturers act as a supplier for secondary manufacturer. After obtaining active ingredients from the 


\begin{tabular}{llll}
\multicolumn{1}{|c|}{ Manufacturers } & Distributors & - Hospitals & Payers \\
- Primary manufacturers & - Drug manufacturers & - Physicians & - Patients \\
- Secondary manufacturers & - Wholesalers & - Gharmacists & - Government \\
& - Third party organizations & Employers
\end{tabular}

Figure 1. Healthcare supply chain

primary manufacturers, the secondary manufacturers are responsible for transforming active ingredients into a useable drug such as capsules, tablets, and solution. It can be said that manufacturer influences pharmaceutical prices, assessing expected demand, future competition and project marketing costs.

The finished products then are distributed to healthcare providers by distributors, wholesalers and manufacturers. Instead of allowing a third party to deliver their products, there are many manufactures that are responsible for distributing their own products allowing them to leverage margin on self-manufactured products to discount the distribution fee. This might solve the problem caused by the third party distributors deliver the substitute products to the hospitals. As it is found that in several cases the third-party distributors cut its inventory stock of the competing product due to reducing cost of stock control. When the stock-out occurs, the hospital may be forced to switch to the readily available of distributor of manufactured goods.

Unlike other industries, healthcare providers are functioned as both supplier and customer. The professional healthcare providers are customers of its manufacturers whereas they are also suppliers, adding value to the material flow through supply chain and also participate in the provision of new information flow (Dobrzykowski and Vonderembse, 2009). Therefore, this contributes to an increasing in cost as the products are controlled by professional healthcare providers, which are not the end users who pay for the products. The products are ordered for maximizing their availability for needs rather than minimizing holding inventory cost. This is based on clinical preference of physicians rooted in their medical training instead of based on cost-benefit analysis or budget constraint (Mustaffa and Potter, 2009; Turhan and Vayvay, 2009). In the next section, we review the literature on the current problems and methods for improvement in healthcare industry.

\section{LITERATURE REVIEW}

\subsection{Current Problems}

The healthcare industry has viewed itself as operates differently from other industry. The point is that the healthcare providers tend to believe they cannot control their production schedule, unlike managers in other manufacturing industries. As a result, they end up with poor control and stem from the years of outdated strategy (Kumar et al., 2008). Decision based on poor quality information provides ineffective healthcare services which negatively affects the outcome of treatment for patients and provides to the healthcare provider with significant and avoidable cost (Gibbons, 2009).

The studied in Shanghai found that three major aspects lead to traceability problems in Implanted Medical Devices (IMD) (Yan, 2009). Firstly, information recorded during the process was inaccurate. Secondly, manufacturers hardly collect the actual use data from hospital so that they are not able to fulfill their post-market responsibilities. Thirdly, the information of IMD used was not transparent so that it is really hard to protect patient safety, rights and interests. This is supported by European expert group's report. Expert group on safe medication practices (2007) proposed that the medication errors occurred in European countries caused by sound-alike or look-alike drug names, similarities in the outer appearance of medicines' packages and labeling as well as unclear or incomplete labeling information.

In the US, healthcare industry also suffers from inconsistent and inaccurate product information which negatively impacts the rest of supply chain. Each year more than $\$ 11$ billion of waste has been spent due to inefficient process, order and invoice error and outdated information technology (Pleasant, 2009). The difficulty faced by NHS, healthcare provider in UK, is that the lack of data standards contributes to many data silos. Data is available in a large volume whereas quality information is in short supply. From the NHS database, it contains 130 different descriptions of one single product. Due to this problem, it means that the analysis of expenditure and demand requirement in term of time and resources across organisations is very costly in term of time and resources (Gibbons, 2009).

Worse, healthcare supply chains exist as highly fragmented systems in which manufacturers, distributors, wholesalers, and providers operate independently from one another. Fragmentation complicates the task of connecting the thousand of partners involved at any stage in the chain (Dobrzykowski and Vonderembse, 2009; Burns et al., 2002). Burns et al. (2002) address all parties in healthcare industry still lack coordinated effort, strategic alliance formation and knowledge sharing. Gibbons (2009) states healthcare is an information intensive environment and the availability of quality information is essential for the delivery of safe and effective healthcare services. Due to lack of information sharing, the supply chain acts more to push products down the chain rather than pull them from the customer (Burns et al., 2002). According to the push strategy, The Chapel Allerton Orthopaedic Centre (CHOC) experienced high stock levels and system integrity problems arising from consignment and vendor managed inventory. The Orthopaedic Centre's supply model, where stock is held on consignment, was hugely inefficient and manufacturers are typically applying a $15-20 \%$ on cost a result (Medwell, 2009). 

Table 1. Problems in healthcare industry

\begin{tabular}{|c|c|c|}
\hline Studies & Highlighted key findings & Problem categories \\
\hline Nicholson (1995) & $\begin{array}{l}\text { Owing to the diverse management structure in hospital, } \\
\text { providing co-ordinate care was difficult }\end{array}$ & Inefficient business process \\
\hline McGrath and More (2001) & Poorly integrated information system & $\begin{array}{l}\text { - Data inconsistency } \\
\text { - Fragmented system }\end{array}$ \\
\hline Burns et al. (2002) & $\begin{array}{l}\text { All parties in healthcare industry still lack coordinated } \\
\text { effort, strategic alliance formation and knowledge sharing }\end{array}$ & $\begin{array}{l}\text { Data inconsistency } \\
\text { - Fragmented system }\end{array}$ \\
\hline McRobbie et al. (2003) & $\begin{array}{l}\text { Inherent efficiencies and recruitment and retention } \\
\text { problems within the pharmacy profession impacts on } \\
\text { healthcare service and patient safety }\end{array}$ & Ineffici \\
\hline Danese (2004) & $\begin{array}{l}\text { The traditional customer managed inventory leads to the } \\
\text { inability to meet changing demand pattern and increased } \\
\text { transportation costs }\end{array}$ & Inefficient \\
\hline EFPIA (2008) & $\begin{array}{l}\text { Medication errors occurred in European countries caused } \\
\text { by sound-alike or look-alike drug names, similarities in the } \\
\text { outer appearance of medicines' packages and labeling as well } \\
\text { as unclear or incomplete labeling information }\end{array}$ & Data incons \\
\hline Kumar et al. (2008) & $\begin{array}{l}\text { Increasing operating cost is caused by the inefficient } \\
\text { centralized supply system and material management }\end{array}$ & Inefficient business process \\
\hline $\begin{array}{l}\text { Dobrzykowski and } \\
\text { Vonderembse (2009) }\end{array}$ & $\begin{array}{l}\text { A fragmented system in healthcare industry limited } \\
\text { communication among all parties }\end{array}$ & Fragme \\
\hline Gibbons (2009) & $\begin{array}{l}\text { Decision based on poor quality information provides } \\
\text { ineffective healthcare services which negatively affects the } \\
\text { outcome of treatment for patients and provide to the healthcare } \\
\text { provider with significant and avoidable }\end{array}$ & Data inconsistency \\
\hline Medwell (2009) & $\begin{array}{l}\text { The Chapel Allerton Orthopaedic Centre (CHOC) } \\
\text { experienced high stock levels and system integrity }\end{array}$ & $\begin{array}{l}\text { Fragmented system } \\
\text { - Inefficient business process }\end{array}$ \\
\hline Pleasant (2009) & $\begin{array}{l}\text { In the US, healthcare industry also suffers from } \\
\text { inconsistent and inaccurate product information which } \\
\text { negatively impacts the rest of supply chain }\end{array}$ & Data in \\
\hline $\begin{array}{c}\text { Sooksriwong and } \\
\text { Bussaparoek (2009) }\end{array}$ & $\begin{array}{l}\text { Inefficient cold chain management during transportation } \\
\text { affects the quality and stability of temperature-sensitive } \\
\text { products }\end{array}$ & Inefficient business process \\
\hline Yan (2009) & $\begin{array}{l}\text { Traceability problems in Implanted Medical Devices } \\
\text { (IMD) in Shanghai }\end{array}$ & Data inconsistency \\
\hline
\end{tabular}

Additionally, it is apparent that inefficient process leads to poor performance and avoidable cost in healthcare industries as activities related to the purchase, distribution, and management of supplies account for about one third of the operating costs of healthcare facilities (Kumar et al., 2008). The Glaxosmithkline, a pharmaceutical company, found that the traditional customer managed inventory is no longer appropriate to the company as it leads to the inability to meet changing demand pattern and increased transportation costs due to inefficient planning and difficulties for the supplier to determine production capacity (Danese, 2004). Sooksriwong and Bussaparoek (2009) found that inefficient cold chain management during transportation affects the quality and stability of products. The Chapel Allerton Orthopaedic Centre (CHOC) in UK had an inefficient inventory management so that it contributed to overstock problem. The centre spent on inefficient inventory management exceeds $£ 3$ million per year (Medwell, 2009). Guy's and St. Thomas hospital faced difficulty because the traditional system of hospital pharmacy has inherent efficiencies and recruitment and retention problems with the pharmacy profession. Due to this problem, it affects directly to hospital service and patient safety (McRobbie et al., 2003). The complicated role of professional healthcare also 
impacts on hospital process. Owing to the diverse management structure in hospital, providing co-ordinate care was difficult (Nicholson, 1995). Table 1 illustrates the problems found in healthcare industry.

It can be seen from the table above that the top two problems are inefficient business process and data inconsistency in the system. Also, fragmented system in the hospital is highlighted. Noticeably, these three problems are inter-related. Data inconsistency leads to fragmented system and inefficient business process. On the other hand, inefficient business process can cause fragmented system which then results in data inconsistency.

\subsection{Enhancing Performance Improvement and Supply Chain Integration}

According to the current situation, we then investigate another perspective of literature review in order to find how healthcare enterprises adopt the strategy to alleviate these problems and improve their operational performance. To promote operational improvement and healthcare supply chain integration, standardisation is of concern. Implementation of supply chain standard data contributes to information synchronisation so that all stakeholders in the industry are able to speak the same electronic language (Kreysa and Denecker, 2009). According to European Federation of Pharmaceutical Industries and Associations (EFPIA)'s report (2008), European countries have experienced implementing standardisation. Each country develops and implements a coding system to their material flow in order to improve healthcare supply chain. At the initial stage, it is used by manufacturers, distributors and pharmacists for logistics purpose whereas, today, it is also widely used for administrative reasons (EFPIA, 2008). In 2007, a premier enterprise, an American healthcare industry provider, accelerates the use of a single Unique Device Identification (UDI) System in healthcare industry by proposing the requirement to their suppliers to incorporate certain standard in order to win contracts (Pleasant, 2009).

Moreover, Shanghai Food and Drug Administration began to implement the IMD traceability system in 2006 due to post-market surveillance purposes. The tracking system covers more than 100 hospitals using IMDs in Shanghai. The IMDs include high-risks devices such as orthopedic internal fixation devices, orthopedic implants, synthetic crystals, breast implants, and pacemakers (Yan, 2009). In Australia, the pharmaceutical industry is one of the first industry groups adopting standard approach to e-commerce. The Pharmaceutical Extranet Gateway (PEG) provides a single common electronic ordering system that allows pharmaceutical wholesalers and suppliers to transact business through the internet with the use of a common EAN-based bar coding or standardised numbering system (McGrath and More, 2001). The implementation of common data standard across the procurement and commercial systems by NHS in UK with its suppliers also enables information to easily transfer between systems. This enables interoperability between systems, allowing automation which reduces the resources required, removes errors, increases compliance and reduces risk (Gibbons, 2009).

Gibbons (2009) highlights that more effective process and better relationships provide a higher quality supply chain. To enable the effective delivery of high quality information organisations on the demand and supply sides the healthcare, network must be able to share data. Currently, healthcare providers attempt to integrate upstream with the manufacturers, wholesalers and distributors (Rossetti, 2008). After implementing procurement eEnablement technologies provide the NHS with an important opportunity to significantly enhance its capacity to manage procurement information, improve its commercial and procurement processes and remove waste and duplication (Gibbons, 2009). In Australia, the Project Electronic Commerce and Communication for Healthcare (PeCC) is developed to introduce e-commerce practices into the health sector with almost 700 suppliers, automating pharmaceutical and other supplies to hospitals. Supply chain communication is facilitated by an internet-based platform allowing more efficient interaction between the pharmaceutical industry's outlet (retail and hospital pharmacies), wholesalers, suppliers and manufacturers (McGrath and More, 2001). In China, Shanghai Food and Drug Administration implements the implantable medical devices traceability system. This system enables healthcare provider to report the data relevant to the use of IMDs via a data reporting platform. The manufacturers can retrieve information about the use of their products. The data collected by FDA enhances traceability of IMD for post-market surveillance purposes (Yan, 2009). The Leed Teaching Hospital works with the suppliers through GHX, the healthcare e-commerce exchange provider, to enrich the data used throughout the supply chain. As a consequence, the hospital gains financial benefit, clinical benefits and procurement and the project also brings about the supplier benefit and supply chain benefits (Medwell, 2009).

It is noticed that healthcare providers who understand information and communication improve their delivery and quality of care. Therefore, they strive to implement information technology so as to enable their patients to access information easier than before. The subject of ehealth service is a massive one (Dean, 2003). NHS Direct, one of healthcare provider in UK, develops an NHS Direct website provides 24/7 access to clinical advice and information, providing self-guidance. It has established itself as Europe's leading since 1999 (Gann, 2003). In Sweden, telemedicine has been tested and/or used in over 100 applications. One telemedical area is radiology where X-ray computer tomography and magnetic camera images are transferred for consultation and so-called second opinion (Eriksson, 2003). There is an effort to enhance a horizontal integration among healthcare providers including hospitals, private clinics, and private radiologists. General Practitioners (GPs) from these organisations decide to join the Rithme project which enable healthcare professional to share information concerning the patients they all treat throughout the entire Nord Pas de Calais region (Hansske, 2003). However, Hansske (2003) found that protecting confidentiality and user's perception may pose threat to information sharing.

Germany is taking the first step to develop and implement a nationwide telematic infrastructure. The major benefits will spring mostly from the integration of Enterprise Resource Planning (ERP) and the development of integrated data flow that supports patient-centered care (Mainz, 2003).

In Italy, the development of the new national healthcare information systems (NSIS) has taken place in the context of 
gradual change. The NSIS would become a "connectivity backbone" between regional IT systems which empower the SSN (Servizio Sanitario Nazionale-National Healthcare service) more efficient and also delivering better services to the individual (Bergamachi, 2003). Kaiser Permanenete-the largest non-profit health maintenance organisation in the USA with 8.4 million members nationwide which signed a $£ 1.6$ billion contract in early 2003 for a highly pervasive Electronic Health Record (EHR) program (Mori, 2003).

In healthcare industry, business process redesign is used to implement organisational transformations towards more customer-focused and cost-effective care (Burns et al., 2002). Levary (1997) studied a re-engineering project in hospital emergencies rooms by emphasizing on the design of physical facility, information management and communication management. McRobbie et al. (2003) studied the introduction of pharmacy service near patient ward to simplify discharge process. Re-engineering pharmacy service resulted in efficiency of service, more appropriate use of skill mix and the quality use of medicines.

Derbyshire Royal Infirmary, a trust in UK, launched a business process re-engineering project. Accident and emergency was selected as a pilot site. This project focuses on changing the role specific culture to create more flexibility and to be more responsive to sudden change in workload (Nicholson, 1995). Gujarat Cancer Research Institution implemented a new re-engineered system. The existing centralized organisational structure was placed with the new decentralized structure. The new organisational has three directors, three deputy directors and the administrative officer at the same level as the deputy director. They are given necessary powers to manage each own department efficiently and effectively (Ramani, 2006).

Kumar et al. (2008) adopted simulation to present the novel re-engineering process in Singapore hospital. They proposed that the role of centralized supply should be diminished. An efficient hospital would receive items from a supplier to go directly to the appropriate unit and this would be the blue print in the redesign of supply chain. Dandenong hospital introduced the re-engineering pre-admission process for colorectal surgery. This project aims at reducing postoperative length of stay and reducing postoperative complications (Monagle et al., 2002). Racine and Davidson (2002) studied the changes in the staff scheduling at Innercity Academic Pediatric Practice. This results in reducing patient waiting time, reducing total visit times, even though resident satisfaction and quality of care indication still remained the same. Toncich et al. (2000) focused on reengineering process in an Australian emergency department. Although changes in operational times were not clinically significant in improvement, the result almost reached statistical significant level. Kumar and Özdamar (2004) suggested the model for re-engineering operational theatre in hospital in order to reduce resource utilization maximize the productivity. Anthony et al. (2005) studied the reengineering of the discharge process by adopting the generalisable method. This brings the significant improvements in patient care.

As described above, improvements in healthcare industry can be summarised as information sharing, and business process re-engineering and standardisation in healthcare data. These are illustrated in Table 2.

Table 2 Interventions for healthcare supply chain improvement

\begin{tabular}{|c|c|c|}
\hline Studies & Highlighted key findings & Intervention \\
\hline Nicholson (1995) & $\begin{array}{l}\text { Changing the role-specific culture to create more flexibility } \\
\text { and to be more responsive to sudden change in workload }\end{array}$ & $\begin{array}{l}\text { Business process re- } \\
\text { engineering }\end{array}$ \\
\hline Levery (1997) & $\begin{array}{l}\text { A re-engineering project in hospital emergencies rooms by } \\
\text { emphasizing on the design of physical facility, information } \\
\text { management and communication management }\end{array}$ & $\begin{array}{l}\text { Business process re- } \\
\text { engineering }\end{array}$ \\
\hline Toncich et al. (2000) & Changes in re-engineering and bed management & $\begin{array}{l}\text { Business process re- } \\
\text { engineering }\end{array}$ \\
\hline $\begin{array}{l}\text { McGrath and More } \\
\text { (2001) }\end{array}$ & $\begin{array}{l}\text { PEG provides a single common electronic ordering system } \\
\text { that allows pharmaceutical wholesalers and suppliers to } \\
\text { transact business through the internet with the use of a } \\
\text { common EAN-based bar coding or standardised numbering } \\
\text { system }\end{array}$ & $\begin{array}{l}\text { Information sharing } \\
\text { Standardisation }\end{array}$ \\
\hline Monagle et al. (2002) & $\begin{array}{l}\text { Dandenong hospital introduced the re-engineering pre- } \\
\text { admission process for colorectal surgery }\end{array}$ & $\begin{array}{l}\text { Business process re- } \\
\text { engineering }\end{array}$ \\
\hline $\begin{array}{l}\text { Racine and Davidson } \\
\text { (2002) }\end{array}$ & $\begin{array}{l}\text { Changes in staff scheduling at Inner-city Academic Pediatric } \\
\text { Practice and resulted in reducing patient waiting time. }\end{array}$ & $\begin{array}{l}\text { Business process re- } \\
\text { engineering }\end{array}$ \\
\hline Bergamachi (2003) & $\begin{array}{l}\text { The development of the new national healthcare information } \\
\text { systems (NSIS) in Italy }\end{array}$ & Information sharing \\
\hline Dean (2003) & Healthcare providers implement information technology so as & Information sharing \\
\hline
\end{tabular}




\begin{tabular}{|c|c|c|}
\hline Studies & Highlighted key findings & Intervention \\
\hline & $\begin{array}{l}\text { to enable their patients to access information easier than } \\
\text { before }\end{array}$ & \\
\hline Eriksson (2003) & $\begin{array}{l}\text { Telemedicine has been tested and/or used in over } 100 \\
\text { applications in Sweden }\end{array}$ & Standardisation \\
\hline Gann (2003) & $\begin{array}{l}\text { NHS Direct, a healthcare provider in UK, develop an NHS } \\
\text { Direct website provides } 24 / 7 \text { access to clinical advice and } \\
\text { information }\end{array}$ & $\begin{array}{l}\text { Information sharing } \\
\text { Standardisation }\end{array}$ \\
\hline Hansske (2003) & $\begin{array}{l}\text { Enabling healthcare professional to share information } \\
\text { concerning the patients they all treat throughout the entire } \\
\text { Nord Pas de Calais region }\end{array}$ & Information sharing \\
\hline Mainz (2003) & $\begin{array}{l}\text { The integration of ERP and the development of integrated } \\
\text { data flow that supports patient-centered care }\end{array}$ & Information sharing \\
\hline McRobbie et al. (2003) & $\begin{array}{l}\text { The introduction of pharmacy service near patient ward to } \\
\text { simplify discharge process }\end{array}$ & $\begin{array}{l}\text { Business process re- } \\
\text { engineering }\end{array}$ \\
\hline Mori (2003) & EHR program in US & $\begin{array}{l}\text { Information sharing } \\
\text { Standardisation }\end{array}$ \\
\hline $\begin{array}{l}\text { Kumar and Özdamar } \\
\text { (2004) }\end{array}$ & $\begin{array}{l}\text { The model for re-engineering operational theatre in hospital } \\
\text { in order to reduce resource utilization maximize the } \\
\text { productivity }\end{array}$ & $\begin{array}{l}\text { Business process re- } \\
\text { engineering }\end{array}$ \\
\hline Ramani (2006) & $\begin{array}{l}\text { Gujarat Cancer Research Institution implemented a new re- } \\
\text { engineered system. The existing centralized organisational } \\
\text { structure was replaced with the new decentralized structure. }\end{array}$ & $\begin{array}{l}\text { Business process re- } \\
\text { engineering }\end{array}$ \\
\hline EFPIA (2008) & $\begin{array}{l}\text { European countries have experienced in implementing } \\
\text { standardisation }\end{array}$ & Standardisation \\
\hline Gibbons (2009) & $\begin{array}{l}\text { The implementation of common data standard across the } \\
\text { procurement and commercial systems by NHS trusts in UK } \\
\text { with information transfer between systems }\end{array}$ & $\begin{array}{l}\text { Standardisation } \\
\text { Information sharing }\end{array}$ \\
\hline Kumar et al. (2008) & $\begin{array}{l}\text { Business process re-engineering in Singapore hospital } \\
\text { improving material management and distribution process }\end{array}$ & $\begin{array}{l}\text { Business process re- } \\
\text { engineering }\end{array}$ \\
\hline Rossetti (2008) & $\begin{array}{l}\text { Healthcare providers strengthen relationship and integrate } \\
\text { information vertically upstream with its suppliers }\end{array}$ & Information sharing \\
\hline Medwell (2009) & $\begin{array}{l}\text { The Leed Teaching Hospital works with the suppliers through } \\
\text { GHX, the healthcare e-commerce exchange provider, to } \\
\text { enrich the data used throughout the supply chain }\end{array}$ & Information sharing \\
\hline $\begin{array}{l}\text { Kreysa and Denecker } \\
\text { (2009) }\end{array}$ & The implementation of GS1 standards in healthcare industry & Standardisation \\
\hline Pleasant (2009) & $\begin{array}{l}\text { The premier healthcare alliance implements global standard } \\
\text { in order to improve its operational performance }\end{array}$ & Standardisation \\
\hline Yan (2009) & $\begin{array}{l}\text { The tracking system plays a crucial role in addressing the } \\
\text { post-market surveillance of those high-risk medical devices }\end{array}$ & Standardisation \\
\hline
\end{tabular}




\begin{tabular}{|c|c|c|}
\hline Problem highlighted in healthcare supply chain & & Intervention improvement \\
\hline $\begin{array}{c}\text { Inefficient business processes } \\
\text { (Nicholson, 1995; McRobbie et al.., 2003; } \\
\text { Danese, 2004; Kumar et al., 2008; Medwell, 2009; } \\
\text { Sooksriwong \&Bussaparoek, 2009) }\end{array}$ & 4 & \begin{tabular}{|c|} 
Business process re-engineering \\
(Nicholson, 1995; Levery, 1997; Toncich et al., 2000; \\
Monagle et al., 2002; Racine \& Davidson, 2002; \\
McRobbie et al., 2003; Kumar \& Özdamar, 2004; \\
Ramani, 2006; Kumar et al., 2008; )
\end{tabular} \\
\hline $\begin{array}{c}\text { Data inconsistency } \\
\text { (McGrath \& More, 2001; Burns et al., 2002; } \\
\text { EFPIA, 2008; Gibbons, 2009; Pleasant, 2009; } \\
\text { Yan, 2009) }\end{array}$ & 4 & $\begin{array}{c}\text { Data standardisation } \\
\text { (McGrath \& More, 2001; Eriksson, 2003; Yan, 2009; } \\
\text { Gann, 2003; Mori, 2003; EFPIA, 2008; } \\
\text { Kreysa \& Denecker, 2009; Pleasant, 2009) }\end{array}$ \\
\hline $\begin{array}{l}\text { Fragmented supply chain system } \\
\text { (McGrath \& More, 2001; Medwell, 2009; } \\
\text { Dobrzykowski \& Vonderembse, 2009) }\end{array}$ & 4 & $\begin{array}{c}\text { Information sharing } \\
\text { (McGrath \& More, 2001; Bergamachi, 2003; } \\
\text { Dean, 2003; Gann, 2003; Hansske, 2003; } \\
\text { Mainz, 2003; Mori, 2003; Gibbons, 2009; } \\
\text { Rossetti, 2008; Medwell, 2009;) }\end{array}$ \\
\hline
\end{tabular}

Figure 2. Mapping framework: Problems in healthcare supply chain against the intervention improvements

The intervention for supply chain improvement from the literature above can be mapped with the problems highlighted in the literature earlier. Business process reengineering leads to business process improvement. Data standardisation can be a platform for the consistency of data. Information sharing is the way for bridging the fragmented supply chain. Figure 2 shows the mapping between problems and intervention improvements for healthcare supply chain.

Having reviewed all literature highlighted problems and intervention improvements for healthcare supply chain, we further investigate the above framework by focused group in the next section.

\section{DATA GATHERING - THAILAND CASE STUDY}

To investigate the healthcare supply chain framework for improvement, several focused groups have been conducted by National Research University Project. In the focused group, we invited various players in healthcare industry including hospital's board of directors, pharmacists, system engineers, information technology staffs, private suppliers, distributors and experts in supply chain. The purposes of these focused groups were to confirm problems and intervention improvements from literature and find out ways to enhance supply chain integration in healthcare.

Each focused group was asked to brainstorm problems in healthcare supply chain. We listed down all problems on the flipchart. Then the participants were asked to prioritise the problems. It is evidenced that the top three issues are confirmed with the literature earlier. We then investigate further from the focused group whether the three intervention improvements can tackle the problems identified. Here we summarize methodology framework in Figure 3.

In the discussion of data standardisation, many mentioned about material identification focusing on drug codification. National standard code on drug has been one of most concerned issues among trading partners in the industry. Healthcare industry involves a complicated network; including manufacturers, distributors, healthcare providers and reimbursement institutions. Each player tends to develop its own drug code for their individual purpose. Manufacturers and distributors develop the code for the management of trade flows and logistical purpose. Healthcare providers adopt a codification system for material management and public health reason while reimbursement institutions implement the codification for selecting an appropriate reimbursement options. Even though these enterprises are in the same chain, they speak different language which affects to the flow of information along the chain.

However, it is impossible to select one of these codification systems and implement to all players in the industries. Since the codification is created by particular player but still lacks of essential information for another player. For example, the manufacturers and distributors' code might differentiate product with regard to package size; however, its customer - healthcare providers require the codification system covering drug strength and dosage form. This has raised the question whether healthcare industry in Thailand should develop the national standard for product identification or select the existing global standard to implement. Therefore, all players in the industry would speak the same language.

Additionally, it has been seen that healthcare industry is a fragmented industry as it consists of a large amount of parties. All these parties tend to operate independently without coordinated effort or any particular concern on alliance formation. Notwithstanding, to enhance integration of healthcare supply chain, it requires trading partner to improve business relationship and share more information. Information sharing among trading partner has been discussed in several focused groups. However, there are two challenges that should be concerned in the healthcare industry before sharing information which are confidentiality and system security. Regarding to confidentiality, it should be considered the extent of which information could be shared to the supplier in order to improve material 


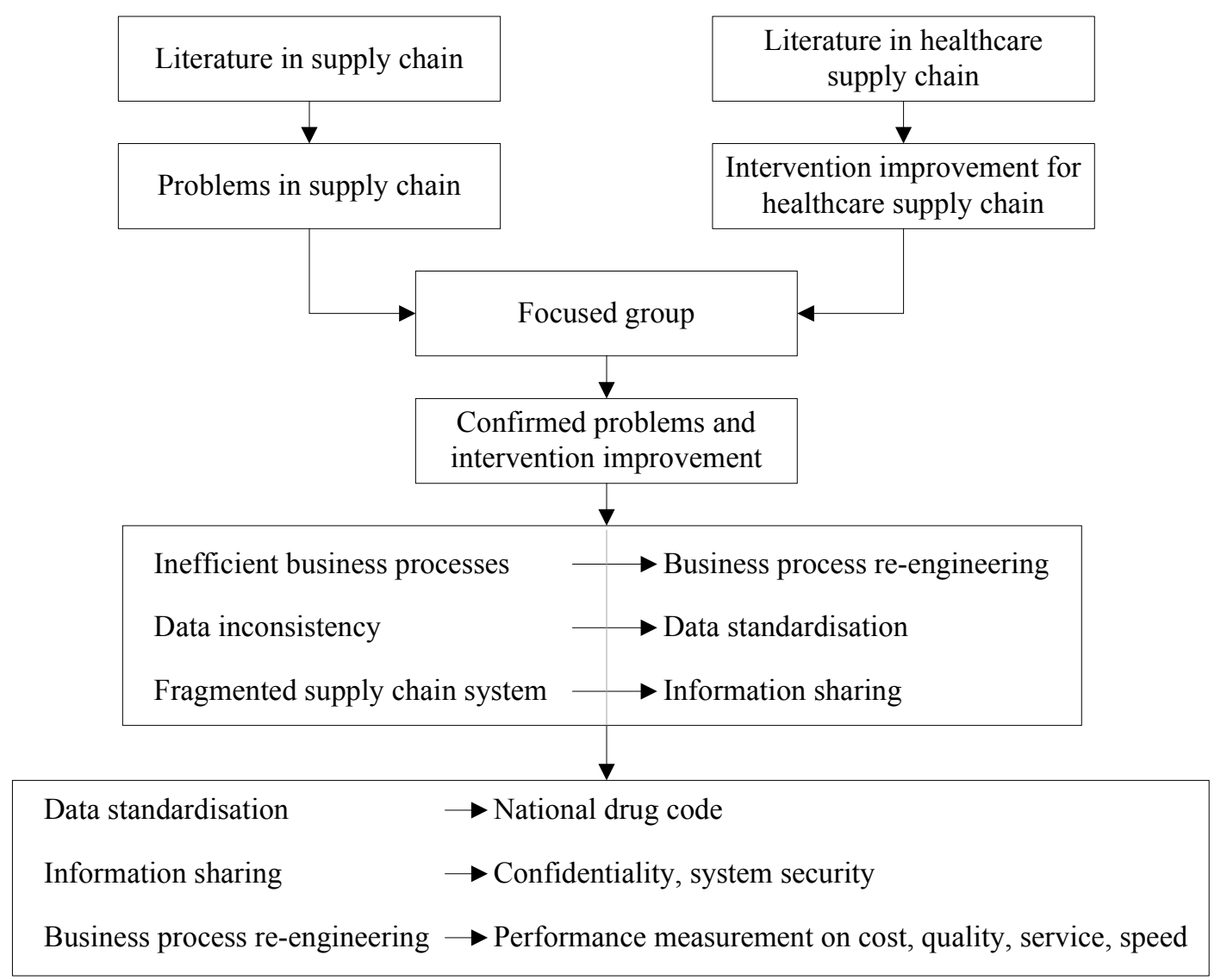

Figure 3. Methodology framework

management and which information that are not allowed to be shared due to the policy or the legislation. Another challenge is the system security. Both trading partners have to decide the level of integration and then considerable effort goes to identify technologies that provide strong system defenses against external attack. Also, costs must be justified.

Business process re-design is another issue that various organisations have taken into account. In the focused group, we have discussed why firms tend to implement this "Change" strategy instead of carry on the former strategy. Problems identified include customer dissatisfaction, difficulties with current material management and higher cost. Healthcare enterprises found that the former strategies are not able to deal with these problems. As a consequence, they decide to implement a business process re-engineering and aim to achieve dramatic improvement in critical performance measurement such as cost, quality, service and speed. The use of information technology is adopted as a contributing factor. It can be concluded that the business process re-engineering is new necessary to improve business efficiency and responsiveness.

In the next section, we summarise all findings above and develop a framework for Thailand healthcare supply chain related issues.

\section{PROPOSED FRAMEWORK FOR THAILAND HEALTHCARE SUPPLY CHAIN}

As mention above, we conducted the literature review to find the current problems occurred in the healthcare industry and the adopted strategy for alleviating these problems. Regarding to the focused group, we conclude that three main problems are inconsistent and inaccurate information, fragmented system, and inefficient business process. As a consequence, the focused group raises three interventions; standardisation, information sharing, and business process re-engineering. Firstly, implementation of drug standard code and system enable suppliers and buyers to identify and navigate the product along the chain. Therefore, this intervention ensures correct products are delivered to correct locations, leading to an increase in patient safety. Secondly, healthcare enterprises tend to implement information technology in order to facilitate product information to their trading partners. Benefit gained from information technology is to enable traceability and contribute to improvements in patient safety. Thirdly, business process re-engineering is also a recommended intervention when the former strategy fails to meet the performance measurement; cost, quality, service, and speed. Regarding to the focused group, it also supports the idea from the literature review. It can be concluded that the need for accurate and consistent accelerates implementation of the data standard. Therefore, there is a need for healthcare enterprises to put an effort to develop the uniform product identification. This is to develop national product identification for healthcare industry in Thailand, otherwise, implement an existing global standard. Additionally, traceability is another concerned. The ability to track and trace product allows the healthcare enterprise to enhance service improvement and error detection effectively. However, to improve traceability, it means healthcare enterprises have to share information with their trading partners. 


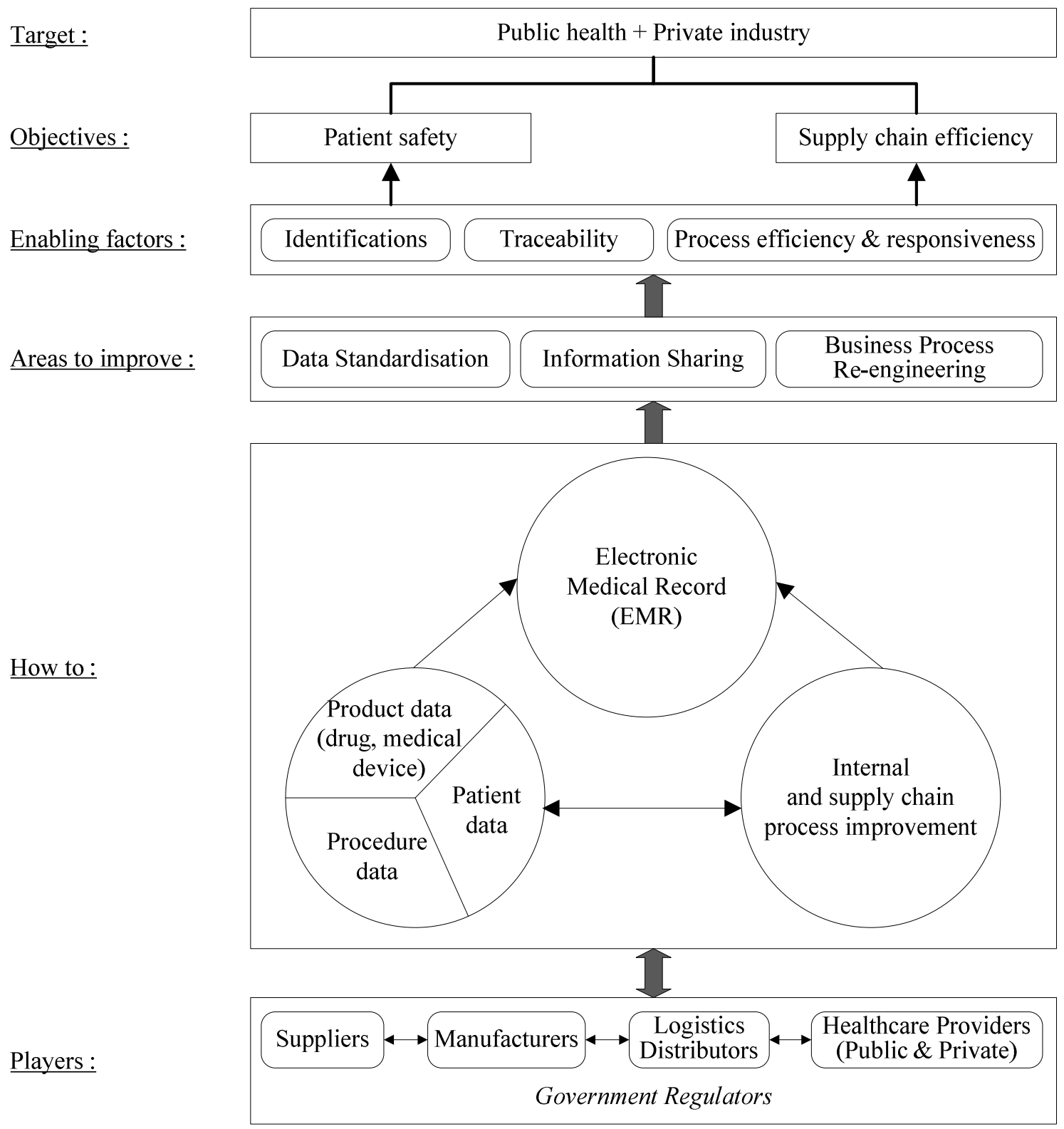

Figure 4 Proposed framework for Thailand healthcare supply chain

As mentioned earlier, data gained from both literature review and focused group provides a clear picture of factor enabling healthcare improvement. This is embedded in the proposed framework. An illustrated framework is shown in Figure 4. The framework emerged from the question how we can implement supply chain thinking into the healthcare industry and how we enable supply chain integration by enhancing collaboration between public and private sectors in the industry. According to the supply chain's concept, it enables process visibility and transparency so that the players from both demand and supply side can see what is happening on the other side. There are also two metrics to consider measuring customer satisfaction which are patient safety and supply chain efficiency.

As noted before, there are three main enabling factors to the achievement which are identification, traceability, and process efficiency and responsiveness. In term of identification, any materials flows, including drug, medical device and patient, along the supply chain have to be identified. Besides, any material flows and data flows can be tracked and traced at any stage in the supply chain. The last factor is process efficiency and responsiveness. This means any process at any stage need to run effectively and respond abruptly.

To achieve the healthcare supply chain objectives patient safety and supply chain efficiency, three areas must be constructed.

1) Data standardisation: this area focused on the unique codification system for all materials and information flown in the chain. These include product data, patient data and procedure data. The objective is to achieve the identifications and traceability of drug, medical device, patient, procedure treated in the chain, and other materials and information flown from the suppliers, manufacturers, distributors, healthcare providers and involved government players in the chain. At this level, it requires all players to implement the same data standard and system so that they can speak the same electronic language.

2) Business process re-engineering: the area emphasizes the improvement of business processes. It is realized that 
before the data standardized deployed, the platform for information exchange must be constructed. This refers to the internal process improvement within hospital and external relationship improvement with its suppliers. Re-engineering concept with lean thinking together with operation managements is needed. This includes workflow analysis, value stream analysis, inventory management, warehouse management, etc.

Information sharing: this area refers to the macro picture. Here, we expect to see the nationwide information sharing in the supply chain. Having prepared for the data standardisation and the supply chain processes streamlined, we need to deploy this Electronic Medical Record-EMR. It is to share and visualize all the data related to all materials and information flown in the supply chain to all users and supply chain players across the country. Supply chain efficiency through the information sharing and patient safety through traceability can significantly reduce medication error problems as well as increasing the quality of life through the country healthcare services.

\section{DISCUSSION AND CONCLUSION}

It is apparent that a number of researches highlighted healthcare problems and proposed various interventions. We then attempt try to find out what healthcare enterprises exactly need to put in action from these interventions. We found that three main concepts behind these interventions: are identification, traceability and process efficiency and responsiveness. Then, we embedded these concepts as enabling factors for healthcare supply chain improvement in Thailand.

Thereafter, we developed the framework for healthcare supply chain improvement in Thailand by first exploring the current problems occurred in the industry. We found that, in Thailand, healthcare supply chain is a new concept. Operations and co-ordinations across players are still neglected. It seems that most hospitals focus only on healthcare performance and undermine its own operational performance. However, supply chain problems, data inconsistency, fragmented system, and inefficient business process, affect not only at operational performance but also lead to negative impacts to patient safety. Due to these problems, it should not only be solved individually but it requires all players in the industry to start implementing supply chain thinking and collaborate with their partners to alleviate the problems. It can be said that the proposed framework is the first step to urge all healthcare players and policy makers to be aware of these problems.

Meanwhile, three pilot projects are conducted according to those three recommended areas. These are:

1) Thailand Standard drug code: this is to respond to the need of data standardisation in supply chain. Since there are a number of coding standards in Thailand, the study focused on pro and con of each using code. It is found that each coding system has been designed for the particular internal purpose. It cannot represent the communications needed in the whole supply chain. New coding system is proposed. The Global Standard Code (GS1) has been adopted. The pilot is to begin with drug codes. Having realized the problem of medication errors and data synchronizations, some major hospitals have agreed to adopt this code. However, the hope goes to public health policy maker to enforce all the players in the chain.

2) Internal process improvement: at the beginning phase, an attempt has been put to the internal process improvement in a pilot hospital. Business process analysis has been conducted. To-be processes are recommended. The pilot area is in the inventory management between wards and warehouse and the warehouse to suppliers vendor managed inventory (VMI) has been introduced. All information architecture with new business processes are designed and recommended.

3) Business architecture in healthcare supply chain: the project is initiated by the importance of information sharing. It is realized that to synchronize the data flow across the chain, smooth platform with strong architecture is a must. Hospital business architecture is a new challenging task in Thailand. The information architecture and technology architecture are also in the composition. Roadmaps to Electronic Health Record (EHR) involves the milestones of successful Enterprise Resource Planning (ERP) and establishment of Electronic Medical Record (EMR) in hospital.

Having initiated all the above pilot projects, it is realized that the target groups of the proposed framework are not only the players in the chain. It cannot be regardless the public health policy maker. They are the influential regulator who drives this healthcare supply chain improvement. The proposed framework here cannot succeed without the enforcement from the regulators which then accelerate all players to adopt the same standard and practices.

\section{ACKNOWLEDGEMENT}

This project is supported by the Office of the Higher Education Commission and Mahidol University under the National Research University Initiative.

\section{REFERENCES}

Anthony, D., Chetty, V.K., McKenna, K., DePaoli, M.R., and Jack, B. (2005). Re-engineering the hospital discharge: An example of a multifaceted process evaluation. Advances in Patient Safety: From Research to Implementation 2, pp. 379 - 394.

Bergamashi, W. (2003). Basic concept model of the new national healthcare information system (NSIS), in Dean, K. (Eds.), Thought Leaders Essay from Health Innovators, Cisco Systems, pp. 72 - 79.

Burns, L.R., DeGraaff, R.A., Danzon,P.M., Kimberly,J.R., Kissick, W.L., and Pauly, M.V. (2002). The Wharton School of the health care value chain, in Burns, L.R. and Wharton School Colleagues (Eds.), The Health Care Value Chain: Producers, Purchasers, and Providers, Jossey-Bass, pp. $3-23$.

Danese, P. (2004). Beyond vendor managed inventory: The Glazosmithkline case, Journal of Supply Chain Forum 5(2), pp. 32 - 40.

Dean, K. (2003). Introduction-essays from health innovators, in Dean, K. (Eds.), Thought Leaders Essay from Health Innovators, Cisco Systems, pp. $4-7$.

Dobrzykowski, D., and Vonderembse, M. (2009). Healthcare supply chain and IS strategy for improved outcomes, in Proceeding of Production and Operations Management Society 20 ${ }^{\text {th }}$ Annual Conference, Orlando, FL, 2009, Manuscript ref. no.: 011-0251.

EFPIA. (2008). Towards safer medicines supply: A vision for the coding and identification of pharmaceutical products in Europe, available at: http://ec.europa.eu/health/files/

counterf_par_trade/doc_publ_consult_200803/114_efpia_en.pdf. (accessed 5 December 2010). 
Eriksson, H. (2003). Sweden-a test ground for telemedicine/telecare, in Dean, K. (Eds.), Thought Leaders Essay from Health Innovators, Cisco Systems, pp. $26-36$.

Gann, B. (2003). Enabling patient access and expertise", in Dean, K. (Eds.), Thought Leaders Essay from Health Innovators, Cisco Systems, pp. 8 -14 .

Gattorna, J. (1998). Strategic supply chain alignment: Best practice in supply chain management, Gower Publishing Company.

Gibbons, R.H. (2009). The NHS Procurement eEnablement program using information to deliver better healthcare, in GS1 (Eds.), GS1 Healthcare Reference Book 2009/2010, GS1 Global Office, pp. 22 25.

Hansske, H.A. (2003). The experience of two unusual French hospitals", in Dean, K. (Eds.), Thought Leaders Essay from Health Innovators, Cisco Systems, pp. $38-48$.

Kreysa, U., and Denecker, J. (2009). GS1 standards in healthcare: raising the bar on patient safety and supply chain efficiency, in GS1 (Eds.), GS1 Healthcare Reference Book 2009/2010, GS1 Global Office, pp. 1 -5 .

Kritchanchai, D., and Suwandechochai, R. (2010). Supply chain management in health sector in Thailand: A case study, International Journal of Services, Economics and Management 2(2), pp. 211 - 224.

Kumar, A., Özdamar, L., and Zhang, C.N. (2008). Supply chain redesign in the healthcare industry of Singapore, International Journal of Supply Chain Management 13(2), pp. 95 - 103.

Kumar, A., and Özdamar, L. (2004). Business process reengineering at the hospitals: A case study at Singapore hospital, in Proceedings of the $18^{\text {th }}$ European Simulation Multiconference, Magdeburg, Germany, 2004 , pp. $308-317$.

Levary, R.R. (1997). Re-engineering hospital emergency rooms: An information system approach, Journal of Health Care Quality Assurance 10(5), pp. $179-191$.

Mainz, R.A. (2003). National policy and strategy for ICT in healthcare: Germany. in Dean, K. (Eds.), Thought Leaders Essay from Health Innovators, Cisco Systems, pp. $66-70$.

McGrath, G.M., and More, E. (2001). Data integration along the healthcare supply chain: The Pharmaceutical Extranet Gateway Project, in Proceeding of the $34^{\text {th }}$ Annual Hawaii International Conference on System Sciences, Maui, Hawaii, 2001.

McRobbie, D., Badnall, R., and West,T. (2003). Assessing the impact of reengineering of pharmacy services to general medical wards, Pharmaceutical Journal 270(7239), pp. $342-345$.

Medwell, G. (2009). Integrating information flows in orthopedics at Leeds Teaching Hospitals NHS Trust, in GS1 (Eds.), GS1 Healthcare Reference Book 2009/2010, GS1 Global Office, pp. 26 - 31.
Monagle, J., Waxman, B., Abourizk, S., Sparrow, M., and Shearer, B. (2002). Preadmission processes may improve length of stay for colorectal surgery, Australia and New Zealand Journal of Surgery $73(40)$, pp. $210-212$.

Mori, A.R. (2003). Cooperative development of the healthcare infostructure for Europe, in Dean, K. (Eds.), Thought Leaders Essay from Health Innovators, Cisco Systems, pp. $90-103$.

Mustaffa, N.H., and Potter, A. (2009). Healthcare supply chain management in Malaysia: A case study, Supply Chain Management: an International Journal 14(3), pp. $234-243$.

Nicholson, J. (1995). Patient-focused care and its role in hospital process reengineering, Journal of Health Care Quality Assurance 8(7), pp. 23 26.

Pleasant, J. (2009). Changes has finally come: U.S. Healthcare industry to implement common data standards to improve safety, reduce cost, in GS1 (Eds.), GS1 Healthcare Reference Book 2009/2010, GS1 Global Office, pp. $6-9$.

Racine, A.D., and Davidson, A.G. (2002). Use of a time-flow study to improve patient waiting times at an inner-city academic pediatric practice, Archives of Pediatrics and Adolescent Medicine 156(12), pp. $1203-1209$.

Ramani, K.V. (2006). Managing hospital suppliers: Process reengineering at Gujarat Cancer Research Institute, India, Journal of Health Organization and Management 20(3), pp. 218 - 226.

Rossetti, M. D. (2008). Inventory manage issue in healthcare supply chains, available www.uark.edu/ rossetti/reports/healthcare_supply_chain_rep.pdf. (accessed 15 December 2010)

Sooksriwong, C., and Bussaparoek, W. (2009). Quality of cold storage drugs transportation and delivery to Thai hospitals, Journal of the Medical Association of Thailand 92(12), pp. 1681 - 1685.

Toncich, G., Cameron, P., Virtue, E., Earlett, J., and Ugoni, A. (2000). Institute for health care improvement collaborative trial to improve process times in an Australian emergency department, Journal of Quality in Clinical Practice 20, pp. $79-86$.

Turhan, S.N., and Vayvay, O. (2009). Modeling of VMI implementation via SOA in a healthcare supply chain. in Proceedings of the $6^{\text {th }}$ European and Mediterranean Conference on Information Systems, Izmir, Turkey, 2009.

Yan, L. (2009). Shanghai Food and Drug Administration: Implement of a post-market traceability program for implantable medical devices adopting unique device identification, in GS1 (Eds.), GS1 Healthcare Reference Book 2009/2010, GS1 Global Office, pp. 10 - 14.

Duangpun Kritchanchai, Ph.D. was engaged as the project leader for several large-scale projects such as the Supply-chain management project for SMEs and the Logistics policy for Rubber supply chain, Thailand Research Fund. Her research interests are in supply chain management, information technology in logistics and supply chain, healthcare supply chain. She is currently serving at Mahidol University, in the capacity of Associate Professor and Director in the Centre of Logistics management, as well as holding the position of Coordinating Chair of Logistics Research Group, Thailand Research Fund. Her email address is duangpun.skr@mahidol.ac.th. 